\title{
Factors predicting the likelihood of return to work for SOCSO's return to work program participants within different employers
}

Roshaimi Mat Rosely

Social Security Organisation, Malaysia. roshaimi.rosely@perkeso.gov.my

Background: Tackling the rising trend of workers suffering from disability due to injuries and diseases, the Malaysian Social Security Organization (SOCSO) introduced the Return to Work (RTW) Program in January 2007. The Return to Work Program provides systematic disability management for Insured Persons with employment injuries and illnesses using a bio psychosocial and multidisciplinary approach to enable them to return to work in a safe and fast manner. In this process, it is the ultimate goal of the Case Manager to place the Insured Person with injuries or illnesses back to the same employer within the same, similar or a different job. Nevertheless there are a large number of Insured Persons who fail to return to their same employer and would therefore require job placement assistance to be placed within the "different employer hierarchy". Note: "Different employer hierarchy" refers to participants who failed to return to work with their previous employers requiring job placement assistance to be placed within new employers.

Objective: This study explores factors predicting the likelihood of return to work among Insured Persons requiring job placement assistance. In the process of placing RTW participants among different employers, SOCSO has seen a drastic shift in the reception of employers wanting to employ persons with disabilities since the program was first implemented. While promotional measures and various interventions are carried out to increase number of participating employers, it is also essential that the readiness of the RTW participant themselves to return to work is evaluated at the beginning of the program to ensure that they will be mentally ready to return to work after being successfully rehabilitated.

Methods: The logistic regression model was used to find significant variables from a sample size of 798 participants which may be used as indicators on the likelihood of RTW participants under job placement assistance in returning to work. Findings From the results, it was found that there were eight (8) significant variables which includes the clients self-perceived self-esteem, skills, health condition, pain tolerance, independence, self-confidence and career goals. It was also found that gender was a subsequent variable which could also be used as a predicting factor in predicting the likelihood of the participant returning to work.

Discussion: In enhancing the quality and efficiency of providing job placement assistance for participants of SOCSO's Return to Work Program, significant indicators as found in this study can be used as a valuable tool in future where Case Managers may use this indicators to design interventions at the beginning of the programme . For instance, if the client had issues with self-esteem from the beginning of the program with low scores, this may suggest that additional counselling interventions and motivational programs may be required to improve the participant's self-esteem with the objective that he is able to return to work as soon as possible. 